\title{
Ultimatum bargaining by children and adults
}

\author{
J.Keith Murnighan ${ }^{\mathrm{a},{ }^{*}}$, Michael Scott Saxon ${ }^{\mathrm{b}}$ \\ ${ }^{a}$ Kellogg Graduate School of Management, Northwestern University, Evanston, IL 60208, USA \\ ${ }^{\mathrm{b}}$ Department of Business Administration, University of Illinois, Champaign, IL 61820, USA
}

Received 31 March 1995; received in revised form 25 January 1996; accepted 11 July 1996

\begin{abstract}
Recent research on ultimatum bargaining, the fact that children often confront and use ultimatums, and theories of developmental psychology all combine to suggest that studying children's ultimatum behavior will be particularly enlightening, both theoretically and with respect to the development of bargaining behavior. The results from two experiments indicate that younger children made larger offers and accepted smaller offers than older participants. Boys took greater strategic advantage of asymmetric information than girls; this dichotomy began with nine-year-olds (third graders) and continued for twelve- and fifteen-year-olds (sixth and ninth graders) as well as for college students. Like adults, children accepted smaller offers when they did not know how much was being divided. Older children required increasingly higher offers, except for college students who were willing to accept considerably less than others. Also, some of the nine-year-olds displayed an extremely strong sense of fairness. The discussion focuses on the development of bargaining strategies and concerns for fairness. (c) 1998 Elsevier Science B.V. All rights reserved.
\end{abstract}

Keywords: Adults; Children; Fairness; Ultimatum bargaining

* Corresponding author. Northwestern University, Kellogg/OB/Leverone/360, 2001 Sheridan Road, Evanston IL 60208, USA. Tel.: +1 847467 3566; fax: +1 847491 8896; e-mail: keithm@nwu.edu 


\section{Introduction}

Fairness and exchange are typical aspects of everyday interpersonal interaction. When encounters intensify and become defined as negotiations, ultimatums become a possible (and sometimes probable) end-game strategy. Recent empirical work in experimental economics has focused considerable attention on the dynamics of ultimatum bargaining; results suggest that a forceful economic prediction derived from models of subgame-perfect equilibria (Selten, 1965) cannot explain a remarkably consistent set of findings. Instead, concerns for fairness are often suggested as an explanation for the results (e.g., Güth and Tietz, 1990).

Although issues surrounding fairness have a long history (e.g., see Plato's Republic), we are not aware of any literature that documents a seemingly fundamental question about fairness and bargaining, that is, how children incorporate issues of fairness in their negotiations. Given anecdotal evidence that young children commonly experience ultimatums and other threats (from their parents, siblings, and peers; Murnighan, 1991), ultimatums appear to be a natural bargaining task for studying age-related behaviors in negotiations. In addition, the literature on the development of fairness concerns can be applied directly to these issues.

Thus, this paper presents a first attempt to study the ultimatum bargaining strategies of both children and adults and represents, in part, a reaction to the surprising absence in the empirical research literature on children's bargaining behaviors and the development of bargaining strategies. This study is an attempt to understand one important area - bargaining - of "the economic world that children are constructing themselves" (Lea et al., 1987, p. 398). It also takes an approach that addresses how children understand and try to solve economic problems (Webley and Lea, 1993, p. 463). As a first step in this endeavor, we combine models of children's perceptions of distributive justice (e.g., Damon, 1980) with theories of rational choice to generate hypotheses about children's and adults' ultimatum bargaining behavior. Fairness and income maximization provide markedly different outlooks on this most basic of bargaining interactions. Specifically, this paper focuses on the formation and resolution of ultimatums by kindergartners (5- and 6-year-olds), third graders (9-year-olds), sixth graders (12-year-olds), ninth graders (15-yearolds), and third year college students (20- to 22-year-olds), as framed by economic, social psychological, and developmental theories of fairness and negotiation. 


\subsection{Ultimatums}

By boiling a negotiation down to its most basic, final event, an ultimatum represents the essence of the endgame in competitive two-party bargaining. In its barest form, as studied here, an ultimatum represents the simplest of negotiations: one person makes an offer; the other can accept it or reject it. An acceptance seals the deal, in the terms proposed by the offerer. A rejection means that both parties receive nothing from the interaction. Unlike many real world negotiations, experiments on ultimatums have generally not allowed final offers to be changed: they are true ultimatums.

Models of subgame-perfect equilibria (Selten, 1965; Stahl, 1972) predict that people will accept any ultimatum offer that is greater than zero (i.e., something is better than nothing). Working backward from the respondent's choices (which in this case are restricted to simply accepting or rejecting an offer) suggests that offerers need not offer much, since rejecting would give respondents a zero payoff. The theory fails to predict the often-repeated observations that (1) people offer more than small amounts (often as much as half) and (2) many people reject offers that are greater than zero (e.g., Roth et al., 1991).

Indeed, the subgame-perfect model's predictions and experimental observations show little relationship to one another in typical ultimatum games (e.g., Ochs and Roth, 1989; Roth, 1995). Adults' offers, in a variety of studies, settings, and countries (e.g., Güth et al., 1982; Güth and Tietz, 1987; Neelin et al., 1988; Ochs and Roth, 1989; Roth et al., 1991) have averaged between $40 \%$ and $50 \%$ of the amount to be divided - much larger than predicted. Reasons proposed for unpredicted large offers have focused on offerers' concerns for fairness (Straub and Murnighan, 1995) or their expectations that respondents may reject small offers (Harrison and McCabe, 1992). Reasons proposed for the unpredicted rejections of small offers have included that: (a) respondents may require some minimum offer, below which they will reject everything (Ochs and Roth, 1989); (b) respondents' concerns for fairness lead them to resist small, unfair offers (Güth and Tietz, 1990); or (c) small offers wound a respondent's pride and generate spiteful rejections (Straub and Murnighan, 1995).

Straub and Murnighan (1995) addressed several of these issues in two experiments which included standard conditions of complete information, where both offerers and respondents knew how much was being divided, and partial information conditions, where respondents did not know how much was being divided. Results indicated that, as before, many respondents who 
knew how much was being divided rejected small offers. Respondents who did not know how much was being divided, however, accepted and were willing to accept much smaller offers (as they have in studies by Kagel et al., 1992, and Croson, 1993), indicating that they did not have some minimally acceptable offer. In fact, people reported being willing to accept such small offers (if offerers would make them) that the subgame-perfect predictions for respondents were finally supported, but only in the partial information conditions.

Offers, however, consistently exceeded predictions in both the complete and partial information conditions. In fact, most participants offered significantly more in the complete information conditions than they did in the partial information conditions: they took advantage of respondents' lack of information and shaded their offers (offering less) when respondents did not know how much they were dividing. Straub and Murnighan (1995) operationally defined this behavior as strategic rather than fair (which was operationally defined as offering the same amount in both information conditions), suggesting, as have other studies (e.g., Harrison and McCabe, 1992; Kahn and Murnighan, 1993), that people raise their offers to avoid potential rejections rather than to be fair to respondents. Recent research (Pillutla and Murnighan, 1995) extends this conclusion, showing that offerers are exploitative as well as strategic, since they reduced the size of their offers when they could add "This is fair" labels to them before submitting them to respondents.

\subsection{Children's approaches to fairness}

The research related to children's bargaining has focused primarily on children's allocation norms (e.g., Streater and Chertkoff, 1976) or their competitiveness in matrix games (e.g., Toda et al., 1978). Studies of the development of expressions of self-interest and fairness have repeatedly relied on a procedure derived from the study of equity models in adults (e.g., Adams, 1963). After two children performed a task, one of them divided a reward. Most designs incorporated false feedback that one child's performance was either equal to or better than the other's. Since this information was provided to both children, it established a basis for differential perceptions of deservingness and different allocation norms. Researchers then categorized actual allocations as reflecting norms of equality, equity (i.e., outcomes that were proportional to performance differences), or some combination of the two (e.g., ordinal equity, where the better performer got more, but not proportionally more, than the poorer performer). Lerner 
(1974) used a method that avoided the allocator's inherent conflict between self-interest and the preferred allocation norm. His "third party" procedure asked child allocators to divide the payoff between two other children with known performance achievements. A final variation (Morgan and Sawyer, 1967; Streater and Chertkoff, 1976) allowed performers to actually negotiate their allocations face-to-face.

The results are consistent with the early stages of the six stage model of moral development by Kohlberg (1976), where children progress from selfinterested rule following to understanding that others have needs to conforming to the Golden Rule. In all three methodological variations, the findings show that younger children are own-gain oriented (e.g., Keil, 1986; McClintock et al., 1977). Wide disparities in performance often led to allocations based on ordinal equity, which gives more to the better performer, but not enough to match the differential performance ratio (Keil and McClintock, 1983). In addition, fair allocations (proportional or ordinal equity or equality) by self-interested allocators increased with age (e.g., van Avermaet and McClintock, 1988).

The model of social reasoning by Damon (1980) also reflects these findings, with children (a) being primarily self-interested prior to five years of age, (b) focusing on equality as a way to prevent conflict from 5 to 7 years of age, and (c) beginning to think in terms of equity thereafter. In contrast to these predictions, Handlon and Gross (1959) found that kindergartners (5- and 6-yearolds) were much more likely to keep a majority of the prize than 4th, 5th, or 6th graders (10- to 12-year-olds), who were most likely to split it equally. Hook and Cook (1979) suggested that children's increasing use of proportional equity matches increases in their ability to calculate and apply proportionality.

Research also shows that children become increasingly competitive with age across several cultural groups (e.g., Kagan and Madsen, 1972; Toda et al., 1978). Taken together, these results revise the early observations of Piaget (1965): not only may concerns for equality peak early, but concerns for and the ability to calculate equity, along with competitive behavior, appear to increase with age.

In the ultimatum bargaining task, however, offerers have no substantive claim for their more powerful position: they have really done nothing to achieve their role as offerer. Thus, equity concerns in the context of ultimatums may be conceptualized as equality.

Operationally, our research follows Straub and Murnighan (1995) and defines $50-50$ offers as perfectly fair. The developmental literature we have reviewed suggests that perfectly fair, equal offers will be most likely for 
younger children, especially kindergartners, as they fit Damon's 5- to 7-yearold category where pushes for equality are strongest. As children get older, their ability to calculate proportionality may also lead to a departure from equality. This depends on whether they acclimate quickly to the role (and the power) of the offerer, as adults seem to do. Thus, we predict that perfect fairness will be most frequent for the youngest children in our studies and tentatively predict that strategic behavior will increase with age.

Hypothesis 1. Younger children will make more equal, 50-50 offers than older children.

Hypothesis 2. Older children will be increasingly strategic as offerers. That is, older offerers will shade (reduce) their offers more and more frequently when respondents do not know how much is being divided.

Previous research on generosity, however, suggests that children become more generous as they get older (e.g., Zarbatany et al., 1985) and that girls are more generous than boys. Thus, if children view the offerer's role as an opportunity to be generous, they may offer more. This provides a contrasting hypothesis and a gender-based hypothesis.

Hypothesis 1a. Older children will make larger, more generous offers than younger children.

Hypothesis 3. Girls will make larger ultimatum offers than boys.

Finally, with respect to their behavior as respondents, a wealth of research (e.g., Mischel and Metzner, 1962) suggests that younger children have a much harder time delaying or refusing gratification than older children. Thus,

Hypothesis 4. Younger children will accept smaller offers than older children.

Previous results for adults showed that they accepted less as respondents when they did not know how much was being divided. There seems to be little reason for predicting different results across different age groups. Thus, the final hypothesis is a replication prediction.

Hypothesis 5. Respondents will accept smaller offers when they do not know how much is being divided than they will when they do know how much is being divided. 
This paper reports the results of two related studies. Study 1 includes children who were enrolled in kindergarten (5- and 6-year-olds), third grade (9-year-olds), and sixth grade (12-year-olds). Unlike previous studies with adults, who could make repeated ultimatum offers and responses in a questionnaire, younger children needed individual instructions to understand and respond to the task. Study 2 used more standard methods and includes sixth and ninth graders (15-year-olds); results from college students reported by Straub and Murnighan (1995) were included for comparison. Sixth graders were included in both studies to provide a basis of comparison between the two experiments.

\section{Study 1}

\subsection{Methods}

\subsubsection{Participants}

Forty-seven children in two kindergarten classes and 40 children in two third grade classes at an elementary school in Champaign, Illinois, and 35 children in the sixth grade classes from the junior high school in Mahomet, Illinois participated in this experiment. Champaign is a university town of about 65,000 people; Mahomet is a rural suburb of Champaign. The kindergartners and third graders represented a mix of racial and socioeconomic backgrounds; sixth graders were primarily Caucasian from a mix of rural and suburban homes.

\subsubsection{Procedures and design}

We used a face-to-face, one-on-one procedure to ensure that the children would understand the task. Three experimenters (the authors and a female associate) asked each child to make a series of choices in the hallway outside their school classroom. Each child made take-it-or-leave-it offers of money and M\&Ms (small, sugar-coated chocolate candies that are popular among American children) and responded to another unidentified child's take-it-orleave-it offers of money and M\&Ms. Half of the participants made offers first; half responded to offers first. As respondents, children were told to imagine another child who had an amount of money (unspecified or $\$ 1$ ) or a number of M\&Ms (unspecified or 10). This other child had to offer them some of it.

If they accepted, they were to imagine that they would receive what they were offered and the other child would get what was left. If they rejected the 
offer, they were to imagine that they received nothing and the other child also received nothing.

In the partial information conditions (which always preceded comparable complete information conditions), they were told that they would not know how much the other child was dividing. The experimenter sequentially displayed offers of $1,2,3,5,10,25$, and 50 cents, in that order, or from 1 to 10 M\&Ms, one at a time, on the table in front of them, and asked whether they would accept or reject each offer. Participants always responded to coin offers before $M \& M$ offers since pilot testing suggested that the appearance of M\&Ms prior to coins seriously impeded younger children's ability to concentrate when they were asked to switch to coins. Offers were discontinued when they had accepted three consecutively.

Prior to implementing the experimental procedures, the experimenters asked kindergartners and third graders whether they could identify and differentiate different coins. All of the third graders knew the differences between and the values of a penny, nickel, dime, and quarter (respectively 1, 5,10 and 25 cents). Kindergartners understood the value of a penny, but often confused the remaining coins. Thus, the results for kindergartners' coin offers were not included in the quantitative analyses; we use their choices for coins only in our description of the qualitative findings.

As offerers in the face-to-face procedure, children formulated ultimatums dividing money first and M\&Ms second. They made partial information offers, dividing \$1 (2 quarters, 2 dimes, 4 nickels, and 10 pennies), before dividing 4, 5 , 10 , and $11 \mathrm{M} \& \mathrm{Ms}$ (small and large amounts of an even and an odd number of $\mathrm{M} \& \mathrm{Ms}$ ), before making complete information offers using the same amounts. During the experiment, the complete or partial information nature of the situation was frequently reemphasized. The experimenters often asked children why they had chosen a particular action. All interactions were tape recorded.

The design included a number of factors, including grades (kindergarten, 3rd, and 6th), gender, information (complete and partial), amounts for M\&M offers (4, 5, 10, and 11), order (offers or responses first), and experimenters. For monetary offers, the design included only two grade levels (3rd and 6th grades); kindergartners were excluded from these analyses. For $M \& M$ offers, all three grades and four amounts were included in the design. Analysis of responses to offers included all three grades as well as gender and information. Order and experimenters were included in preliminary analyses to test for potentially biasing effects.

Teachers and administrators at the schools required that the children not be provided any direct compensation (i.e., either money or M\&Ms); they 
received no money or candy as a result of their offers or responses. Although this was not as desirable as providing them with real outcomes, the children responded with considerable interest and involvement in the task. Also, although debate about the value of tangible incentives continues (Roth, 1995), Thaler (1987) reviewed several studies showing no differences in effects for real and hypothetical payments and concluded that experiments that did not include financial incentives still provided important data. In the current studies, each kindergarten and third grade class received a $\$ 50$ gift for the students' participation. The junior high school received a $\$ 200$ contribution to their general fund for the sixth graders' participation. Children were given this information if they asked. A report of the results of the study were provided to the children's instructors and principals with an offer to present and discuss the results with their classes.

Research has recently raised the possibility that a lack of anonymity may lead to increases in offer sizes. Hoffman et al. (1994) found that, in dictator games, anonymity increased the amount of money dictators claimed. Bolton and Zwick (1995), however, report data showing that the effects of anonymity in ultimatum games are considerably less severe. In this study, the use of a face-to-face procedure may have boosted the size of the children's offers; this effect, however, is likely to be consistent across conditions. Given the need to insure that the children understood the procedures, more anonymous procedures were not feasible.

\subsubsection{Dependent variables and analyses}

The primary dependent variables for offerers were the value of their coin and $M \& M$ offers. For respondents, it was their lowest acceptable offers for coins and M\&Ms. Offerers were also operationally defined as strategic, fair, or perfectly fair (Straub and Murnighan, 1995). Offerers were defined as fair when they made identical offers in the complete and partial information conditions. Perfectly fair offers, in addition, were always 50-50. Strategic offerers shaded, offering less in the partial than in the complete information conditions. In the few cases when partial information offers exceeded complete information offers, they were classified as fair.

The observed distributions of offers and responses in both information conditions did not satisfy the assumptions of normality or homogeneity of variance for ANOVA; the data also did not satisfy the sphericity assumptions of the mixed-model approach to within-subjects analyses. However, betweensubjects ANOVAs are robust with respect to departures from the normality and homogeneity assumptions (Maxwell and Delaney, 1990). Moreover, the 
multivariate approach to within-subjects analyses does not require sphericity and is robust with respect to departures from normality. Therefore, all within-subjects analyses used the multivariate approach.

ANOVAs of M\&M offers and lowest acceptable offers (responses) for coins and M\&Ms included two between subjects factors, grades (kindergarten, third, and sixth) and gender (boys and girls), and two repeated factors, information (partial and complete) and amounts (4, 5, 10, and 11 for $\mathrm{M} \& \mathrm{Ms})$. Since kindergartners did not understand the value of different coins, their responses were not included in a similar analysis of coin offers. Note that we use grades rather than age as a factor since grades (kindergarten, third, sixth) are quite distinct in our sample even though age may have varied somewhat within each grade.

We also present a series of qualitative observations. Finally, since consistency is one hallmark of rational behavior (Bazerman, 1994), we measured the consistency of participants' behavior across and within their roles as offerers and respondents. In particular, correlations identified: (1) whether children were consistent (generous or stingy) offerers for the two commodities (money and candy); (2) whether they consistently accepted (or rejected) the offers they received; and (3) whether their offers were related to their responses, i.e., they were willing to make and accept small (or large) offers.

\subsection{Results}

The results are presented in three stages: (1) order and experimenter effects; (2) overall analyses, tests of the hypotheses, and data on age-related bargaining behaviors and strategies; and (3) qualitative and correlational findings. Non-significant effects and results that are not pertinent to either the hypotheses or developmental processes are not reported but are available from the authors.

Tests of experimenter and order effects yielded only one significant effect, indicating that third grade respondents in the face-to-face procedure had more moderate lowest acceptable coin offers $[F(2,29)=4.44, p<0.05]$ for the second author (means of 4.5 and 6.2 cents for the partial and complete information conditions; $n=25$ ) than for the other two experimenters (means of 1.8 and 18.7 cents, respectively; $n$ 's $=5$ and 10). Given the large number of possible effects for experimenters ( 24 across the different conditions and dependent variables), odds were good that one would be significant. Thus, we felt justified in pooling the data over experimenters and order, especially since the largest of the experimenter conditions yielded the most moderate results. 


\subsubsection{Offers}

Significant effects for the third and sixth graders' monetary offers included grade $[F(1,60)=20.92, p<0.01]$, information $[F(1,60)=12.54, p<0.01]$, and gender $\times$ information $[F(1,60)=6.35, p<0.02]$. Overall, third graders offered significantly less than sixth graders ( 32.54 versus 47.58 cents); average offers were significantly higher ( 42.25 versus 37.35 cents) when the amount to be divided was complete rather than partial information. The interaction indicated that females shaded their offers only moderately (on average, from 42.32 in the complete information condition to 40.42 cents in the partial) while males shaded more (averages of 42.18 and 34.27 cents). The significant interaction clearly resulted from the boys' relatively small partial information offers.

Frequency counts for the number of fair, perfectly fair, and strategic monetary offerers, however, indicated that girls were only slightly more often categorized as fair $(n=17)$ than they were as strategic $(n=14)$ and that third grade boys tended to be strategic (16 of 21) while sixth grade boys tended to be perfectly fair (15 of 23 ). Thus, the means and medians are slightly deceptive, and the conclusion that boys were generally strategic while girls were generally fair is more true, in this sample, for third than for sixth graders. It also suggests that when girls made strategic offers, they shaded their partial information offers less than boys did, and that sixth grade boys who did shade their offers shaded them a lot.

For M\&M offers, the only significant effect was a grade $\times$ gender $\times$ amount interaction $[F(6,276)=2.81, p<0.02]$ which indicated that, while the median offer for offerers dividing 4 and $10 \mathrm{M} \& \mathrm{Ms}$ was typically 2 and 5, respectively, girls tended to offer more than half ( 3 and 6 ) while boys offered less than half ( 2 and 5) when they were dividing 5 and $11 \mathrm{M} \& \mathrm{Ms}$.

\subsubsection{Responses}

The only significant effect for responses to monetary ultimatums was a main effect for information $[F(1,60)=17.73, p<0.001]$. As in previous studies with adults, children were willing to take significantly less (on average, 4.65 cents) when they did not know how much was being divided than when they did (10.65 cents). The analysis of children's responses to $\mathrm{M} \& \mathrm{M}$ offers yielded no significant effects that were pertinent to the hypotheses.

Analysis of the frequency of acceptances of one penny and one M\&M indicated that kindergartners accepted offers of one penny or one M\&M more than third and sixth graders, $[F(2,120)=3.70, p<0.03]$ : they accepted 
$67 \%$ of the one penny offers and $76 \%$ of the one M\&M offers, compared to $27 \%$ and $27 \%$ for third graders and $40 \%$ and $62 \%$ for sixth graders, supporting Hypothesis 4. Overall, respondents accepted one M\&M more frequently than one penny, $[F(1,120)=9.95, p<0.005]$.

\subsubsection{Qualitative and correlational results}

There were three noteworthy qualitative findings. Although many kindergartners did not understand the value of the different coins, they made a rough quantitative division of the coins when they were making offers. Many simply separated the pile of coins into two approximately equal groups and shoved one across the table as their offer. More importantly, approximately $12 \%$ of the kindergartners gave the other child all of the coins and all of the M\&Ms. We did not see this behavior in any other group.

Second, more than half of the third graders who were dividing 4, 5, 10, and $11 \mathrm{M} \& \mathrm{Ms}$ offered 2, 3, 5, and 6 (or some slight variation of this pattern) in both the complete and partial information conditions. When they were dividing 5 or 11 M\&Ms, many asked whether they could cut one in half. As noted, girls were more likely to offer the odd M\&M; boys were more likely to keep it.

In addition, when they responded to $\mathrm{M} \& \mathrm{M}$ offers from another child and they knew that $10 \mathrm{M} \& \mathrm{Ms}$ were being divided (the complete information condition), 13 of the 40 third graders $(35.5 \%$; six boys and seven girls) rejected $1,2,3$, and 4 , accepted 5 , and rejected $6,7,8,9$, and 10 . A lack of fairness, for them or for the other child, was the reason given for rejecting unequal offers.

We checked whether participants were consistent by converting offers and minimally acceptable offers (responses) to percentages of the amount offered, and calculating intercorrelations between and among their offers and their responses. Children were consistent respondents to $M \& M$ and monetary offers; their responses were highly correlated ( 3 of 4 coefficients were significant; $0.10 \leqslant r$ 's $\leqslant 0.49, p<0.05)$. They were also consistent offerers: correlations among monetary offers and among M\&M offers were significant in 28 of 29 instances; correlations between monetary and M\&M offers led to 9 of 16 significant correlations. No significant correlations (out of 20) resulted, however, between responses and offers. Thus, children tended to be internally consistent as offerers or as respondents, but they were not consistent when they shifted from being respondents to offerers or vice versa. 


\subsection{Discussion}

The data from Study 1 provide mixed support for the hypotheses. Hypothesis 5, that respondents would accept less when they did not know how much was being divided, was clearly supported for monetary offers. Thus, the current findings were consistent with those for adults.

Hypothesis 4 suggested that younger children would accept smaller offers than older children. Kindergartners accepted offers of a single penny or M\&M more often than the older children in this sample. But third graders' frequent use of a stringent criterion for fairness, which led to many rejections, runs counter to the hypothesis. Overall, support is mixed.

Hypothesis 3 was primarily supported: girls did tend to offer more than boys. They did so particularly when they divided an odd number of M\&Ms ( 5 or 11 ) and when the respondent did not know how much money they were dividing (the partial information conditions), where, unlike the boys, they shaded their offers only slightly.

Hypothesis 2 suggested that older offerers would be increasingly strategic. Hypothesis 1 predicted that younger children would be perfectly fair more than older children; Hypothesis 1a suggested that younger children would not be as generous as older children. The data are not consistent for any of these hypotheses. Third graders shaded more than kindergartners. However, sixth graders were more often fair than strategic, supporting the notion that older offerers were more generous. But kindergartners were the only offerers to offer everything. Their intentions never seemed strategic; when they did not offer half, the size of their offer seemed to be based more on an inability to calculate what was exactly half than anything else.

\section{Study 2}

Study 1 investigated the bargaining behavior of young children in a simplified, face-to-face procedure. Study 2 extends this research to older children, 6th and 9th graders who average 12 and 15 years of age, respectively, and compares their responses to young adults (college students) using standard response formats that increase participants' anonymity. Rather than responding one-on-one with an experimenter, respondents in Study 2 completed written questionnaires anonymously. By extending the age of the children we studied, we provide a more complete picture of the changes and development of bargaining behavior from younger children to adults. 


\subsection{Methods}

\subsubsection{Participants}

Sixty additional students from the same sixth grade classes participated in this experiment, along with 58 students from three ninth grade classes from the high school in Urbana, Illinois, and 145 students from three undergraduate classes at the University of Illinois. Urbana is Champaign's sister city (they are not separated geographically) and has approximately 35,000 residents; the ninth graders represented a mix of racial and socioeconomic backgrounds. As noted, the sixth graders were primarily Caucasian from a mix of rural and suburban homes. The undergraduate population at the University of Illinois primarily draws middle and upper middle class students from the city of Chicago and the state of Illinois; the students in this study were enrolled in an introductory management class designed primarily for third year students (20 years of age, occasionally older).

\subsubsection{Procedures}

All participants responded to a paper-and-pencil questionnaire to ensure that their responses were comparable to those from previous research. The questionnaire asked them to first act as ultimatum respondents and then as ultimatum offerers. (Some of the college students, as noted below, only acted as respondents, and none responded to or made ultimatums with M\&Ms as prizes.) Sixth and ninth graders' questionnaires began with eight "no strings attached" offers, where respondents were simply offered amounts of money (ranging from 1 cent to \$5) that they could accept or reject. The instructions emphasized that their responses would not affect any other person. (Technically, of course, this cannot be true: any winnings had to come from somewhere. But we tried to diffuse the source and, if asked, emphasized that no other individual provided these funds.) They were also asked the lowest amount they would accept in this and each of the following conditions. The "no strings" condition was included to determine just how low their smallest acceptable offers might go.

Participants then responded to offers, first without knowing how much was being divided (partial information) and then when they did (complete information). Both sets of offers were in the same range as those from the no strings attached condition, but with slightly different values, to reduce suspicion. Offerers ostensibly divided $10 \mathrm{M} \& \mathrm{Ms}$ and monetary amounts ranging from $\$ 1$ to $\$ 1$ million. Participants knew these amounts in the complete information condition. They also knew that amounts of $\$ 100$ or more were 
strictly hypothetical; responses to or offers of amounts less than $\$ 100$, however, were included in a lottery, described below, that determined their potential payoffs.

Participants then made their own ultimatum offers, first when they knew that respondents did not know how much was being divided, and then when the amount was shared (complete) information. They divided 4, 5, 10, and 11 M\&Ms and monetary amounts ranging from $\$ 1$ to $\$ 1$ million.

The college students responded to a similar series of questions. Two classrooms totalling 94 students responded to the no strings, partial, and complete information monetary offers but did not formulate offers. One other classroom of 51 college students participated in a different experiment and responded to and made all of the monetary offers but did not respond to no strings offers.

\subsubsection{Dependent variables and analyses}

The dependent variables and analyses were similar to those in Study 1. Comparisons across monetary amounts were obtained by analyzing the percentage offered. Monetary (raw and percentage) and M\&M offers were included in separate four-factor ANOVAs, including two between subjects factors, grades (sixth, ninth, and college) and gender (females and males), and two repeated factors, information (partial and complete) and amounts $(4,5$, 10 , and $11 \mathrm{M} \& \mathrm{Ms} ; \$ 1, \$ 10, \$ 30, \$ 50, \$ 100, \$ 1000$, and $\$ 1$ million). Lowest acceptable offers (responses) were analyzed in two three-factor analyses, one including all three information conditions (no strings, partial, and complete) but restricted to the $\$ 10$ amount, the other including only the complete information condition but including all of the amounts.

\subsubsection{Incentives}

As noted, the sixth graders' school received a contribution for their participation. In addition, three members from one college class won money depending on one of their responses to the offers. After completing many responses, three names were randomly chosen from the class roster and one of each of their responses to offers of $\$ 100$ or less was also randomly chosen. That response determined their payoff: if they accepted, they were paid the amount offered; if they rejected it, they received nothing.

The two classes that did not respond to the no strings offers each had two winners, one for their offers and responses and one for a set of utility questions that were part of another study (Straub and Murnighan, 1995) not reported here. In each case, the winners and one of their responses (of offers 
or responses of $\$ 100$ or less) were randomly chosen. If they had accepted a particular amount, they received it. If they had rejected it, they received nothing. They knew this in advance. Although expected values for each response were quite low (given the low probability that any single response would be selected as a winner), awarded prizes ranged from a dime to $\$ 97.50$. Bolle (1990) reports that such lottery procedures led to no differences from other procedures that make smaller, direct payments to each respondent, suggesting that this payoff scheme is reasonable and effective. After a post hoc questionnaire and the lottery, college students participated in a lengthy debriefing discussion, as did the ninth grade classes.

\subsection{Results}

\subsubsection{Offers}

The significant effects from the ANOVAs for raw monetary offers and as a percentage of the amount divided are shown in Table 1. Main effects indicated that sixth graders offered more (on average, $43 \%$ of the amount they were dividing) than ninth graders $(37 \%)$ or college students $(35 \%)$. Average

Table 1

Analysis of variance summaries for monetary offers for sixth and ninth graders and college students

\begin{tabular}{|c|c|c|c|c|c|}
\hline \multirow[t]{2}{*}{ Factor } & \multicolumn{3}{|c|}{ Raw offers } & \multicolumn{2}{|c|}{$\%$ of Amt divided } \\
\hline & df & $F$ & $p<$ & $F$ & $p<$ \\
\hline \multicolumn{6}{|l|}{ Mixed model analyses } \\
\hline Grade & 2,135 & 6.60 & 0.002 & 4.74 & 0.01 \\
\hline Gender & 1,135 & 7.46 & 0.007 & 2.97 & 0.087 \\
\hline Information & 1,135 & 32.86 & 0.001 & 43.30 & 0.001 \\
\hline Grade $\times$ Gender & 2,135 & 1.09 & ns & 2.30 & 0.104 \\
\hline Grade $\times$ Info & 2,135 & 1.67 & 0.193 & 5.17 & 0.007 \\
\hline Gender $\times$ Info & 1,135 & 6.46 & 0.012 & 8.81 & 0.004 \\
\hline Grd $\times$ Gender $\times$ Info & 2,135 & 0.24 & $\mathrm{~ns}$ & 1.58 & 0.209 \\
\hline \multicolumn{6}{|l|}{ Multivariate analyses } \\
\hline Amount & 7,129 & 208.53 & 0.001 & 3.89 & 0.001 \\
\hline Grade $\times$ Amount & 14,260 & 1.98 & 0.019 & 2.09 & 0.013 \\
\hline Gender $\times$ Amount & 7,129 & 2.33 & 0.028 & 1.61 & 0.137 \\
\hline Grade $\times$ Gender $\times$ Amt & 14,260 & 0.82 & ns & 0.59 & ns \\
\hline Info $\times$ Amount & 7,129 & 6.37 & 0.001 & 1.87 & 0.080 \\
\hline Grade $\times$ Info $\times$ Amt & 14,260 & 1.27 & 0.227 & 0.87 & ns \\
\hline Gender $\times$ Info $\times$ Amt & 7,129 & 2.56 & 0.152 & 0.70 & ns \\
\hline Grd $\times$ Gndr $\times$ Info $\times$ Amt & 7.129 & 0.85 & ns & 0.74 & ns \\
\hline
\end{tabular}


offers were higher when there was complete information about the amount to be divided ( $43 \%$ versus $35 \%$ in the partial information conditions). Females made larger offers than males, but only for raw and not for percentage offers, due to the large amounts ( $\$ 1$ million) having a strong impact on the means, supporting Hypothesis 3. The effect for amount divided for raw offers was clearly a function of the manipulation. The more revealing effect was for the percentage of the amount divided, which showed that the offered percentage dropped as the amount increased.

The means and medians from the grade $\times$ information interaction for percentage of the amount divided are shown in Table 2. Offers dropped and strategic behavior (shading in the partial information conditions) increased as the age of the respondents increased (particularly for the medians), supporting Hypotheses 1 and 2 but not 1 a.

The gender $\times$ information interaction for percentage offers indicates that, like the third and sixth graders in Study 1, males shaded their offers more than females. Across both gender and age groups, the median percentage offer in the complete information conditions was $50 \%$; in partial information, females' median offer was $42.3 \%$ while males' was only $32.9 \%$. As in Study 1, these data support Hypothesis 3 in the partial information conditions.

Frequencies of fair, perfectly fair, and strategic monetary offerers indicate that sixth grade girls were most often perfectly fair, as were sixth grade boys. Ninth grade and college females were split between being fair or perfectly fair and being strategic, and were more strategic as the amounts increased. Ninth

Table 2

Monetary offers (in percentages of the amount divided) by sixth and ninth graders and college students in the information conditions

\begin{tabular}{lll}
\hline Grades & \multicolumn{2}{l}{ Information } \\
\cline { 2 - 3 } & Partial (\%) & Complete $(\%)$ \\
\hline Sixth & & \\
$M$ & 41.0 & 44.3 \\
$\quad$ Median & 48.7 & 50 \\
Nineth & & 42.7 \\
$M$ & 32.2 & 50 \\
Median & 33.3 & 39.3 \\
College & & 45 \\
$M$ & 29.8 & \\
$\quad$ Median & 25.4 & \\
\hline
\end{tabular}


grade and college males showed an inclination toward strategic offers, especially when the amounts were $\$ 10$ or more. (The frequencies, for both studies, are shown in Table 3.) These data also support Hypothesis 2.

Table 3

Frequencies of fair, perfectly fair, and strategic offerers for monetary offers for Studies 1 and 2

\begin{tabular}{|c|c|c|c|c|c|c|c|}
\hline \multirow{2}{*}{$\begin{array}{l}\text { Amount } \\
\text { divided } \\
(\$)\end{array}$} & \multirow[t]{2}{*}{ Study 1} & & \multicolumn{2}{|c|}{ Third Grade } & \multicolumn{2}{|c|}{ Sixth Grade } & \\
\hline & & & Females & Males & Females & Males & \\
\hline \multirow[t]{5}{*}{1} & Fair & & 6 & 3 & 2 & 2 & \\
\hline & Perfectly Fair & & 5 & 2 & 4 & 15 & \\
\hline & Strategic & & 8 & 16 & 6 & 6 & \\
\hline & \multirow[t]{2}{*}{ Study 2} & \multicolumn{2}{|c|}{ Sixth Grade } & \multicolumn{2}{|c|}{ Ninth Grade } & \multicolumn{2}{|l|}{ College } \\
\hline & & Females & Males & Females & Males & Females & Males \\
\hline \multirow[t]{3}{*}{1} & Fair & 2 & 4 & 1 & 3 & 1 & 0 \\
\hline & Perf Fair & 24 & 20 & 10 & 10 & 16 & 12 \\
\hline & Strategic & 1 & 9 & 8 & 10 & 8 & 8 \\
\hline \multirow[t]{3}{*}{5} & Fair & 4 & 3 & 1 & 2 & 1 & 1 \\
\hline & Perf Fair & 17 & 19 & 11 & 7 & 13 & 11 \\
\hline & Strategic & 4 & 11 & 7 & 14 & 11 & 8 \\
\hline \multirow[t]{3}{*}{10} & Fair & 2 & 3 & 2 & 1 & 0 & 0 \\
\hline & Perf Fair & 20 & 18 & 7 & 9 & 16 & 7 \\
\hline & Strategic & 4 & 12 & 10 & 13 & 9 & 13 \\
\hline \multirow[t]{3}{*}{30} & Fair & 6 & 2 & 2 & 2 & 2 & 3 \\
\hline & Perf Fair & 16 & 18 & 8 & 9 & 13 & 9 \\
\hline & Strategic & 4 & 12 & 9 & 12 & 10 & 8 \\
\hline \multirow[t]{3}{*}{50} & Fair & 3 & 3 & 2 & 3 & 0 & 2 \\
\hline & Perf Fair & 19 & 18 & 8 & 9 & 11 & 9 \\
\hline & Strategic & 4 & 12 & 9 & 12 & 14 & 9 \\
\hline \multirow[t]{3}{*}{100} & Fair & 3 & 3 & 2 & 3 & 3 & 1 \\
\hline & Perf Fair & 20 & 17 & 5 & 6 & 10 & 7 \\
\hline & Strategic & 4 & 12 & 12 & 14 & 12 & 12 \\
\hline \multirow[t]{3}{*}{1000} & Fair & 2 & 3 & 1 & 1 & 0 & 1 \\
\hline & Perf Fair & 18 & 18 & 8 & 7 & 11 & 8 \\
\hline & Strategic & 7 & 11 & 10 & 15 & 14 & 11 \\
\hline \multirow[t]{3}{*}{1 million } & Fair & 3 & 1 & 2 & 1 & 2 & 0 \\
\hline & Perf Fair & 20 & 18 & 6 & 7 & 12 & 10 \\
\hline & Strategic & 4 & 14 & 11 & 14 & 11 & 10 \\
\hline
\end{tabular}


The information $\times$ amount and grade $\times$ amount interactions (see Tables 4 and 5) show that shading and the differences between the grades increased as the amounts increased. The median offers indicate that offerers did not shade when they were offering one dollar, but they shaded about $10 \%$ for larger amounts and increased shading to $20 \%$ for offers dividing $\$ 1$ million. Sixth graders' median offers (across both information conditions) were always half of the amount to be divided; older students' median offers for amounts greater than $\$ 1$ were always less than half, with college students typically offering somewhat less than ninth graders. This is more support for Hypothesis 2 .

Analysis of M\&M offers for sixth and ninth grade children yielded significant effects for information $(F(1,113)=816.37, p<0.001)$ and

Table 4

Monetary offers (in dollars) by older offerers in the information and amount conditions

\begin{tabular}{|c|c|c|c|}
\hline \multirow{2}{*}{$\begin{array}{l}\text { Amount divided } \\
(\$)\end{array}$} & & \multicolumn{2}{|l|}{ Information } \\
\hline & & Partial & Complete \\
\hline \multirow[t]{3}{*}{1} & $M$ & 0.40 & 0.47 \\
\hline & $\mathrm{SD}$ & 0.18 & 0.13 \\
\hline & Median & 0.50 & 0.50 \\
\hline \multirow[t]{3}{*}{5} & $M$ & 1.90 & 2.20 \\
\hline & $\mathrm{SD}$ & 0.79 & 0.63 \\
\hline & Median & 2.00 & 2.50 \\
\hline \multirow[t]{3}{*}{10} & $M$ & 3.65 & 4.43 \\
\hline & $\mathrm{SD}$ & 1.85 & 1.38 \\
\hline & Median & 4.00 & 5.00 \\
\hline \multirow[t]{3}{*}{30} & $M$ & 10.70 & 12.46 \\
\hline & $\mathrm{SD}$ & 5.86 & 4.13 \\
\hline & Median & 10.00 & 15.00 \\
\hline \multirow[t]{3}{*}{50} & $M$ & 17.09 & 21.08 \\
\hline & $\mathrm{SD}$ & 9.52 & 7.19 \\
\hline & Median & 20.00 & 25.00 \\
\hline \multirow[t]{3}{*}{100} & $M$ & 32.84 & 38.27 \\
\hline & $\mathrm{SD}$ & 20.33 & 44.16 \\
\hline & Median & 40.00 & 50.00 \\
\hline \multirow[t]{3}{*}{1000} & $M$ & 308.69 & 409.88 \\
\hline & $\mathrm{SD}$ & 230.51 & 181.25 \\
\hline & Median & 400.00 & 500.00 \\
\hline \multirow[t]{3}{*}{1 million } & $M$ & 312,452 & 418,152 \\
\hline & $\mathrm{SD}$ & 295,699 & 228,468 \\
\hline & Median & 300,000 & 500,000 \\
\hline
\end{tabular}

Note: $n$ 's ranged from 167 to 169 . 
Table 5

Monetary offers (in dollars) by older offerers for the grade and amount conditions

\begin{tabular}{|c|c|c|c|c|}
\hline \multirow{2}{*}{\multicolumn{2}{|c|}{$\begin{array}{l}\text { Amount divided } \\
(\$)\end{array}$}} & \multicolumn{3}{|l|}{ Grade } \\
\hline & & Sixth & Ninth & College \\
\hline \multirow[t]{3}{*}{1} & $M$ & 0.46 & 0.41 & 0.42 \\
\hline & $\mathrm{SD}$ & 0.12 & 0.15 & 0.13 \\
\hline & Median & 0.50 & 0.45 & 0.50 \\
\hline \multirow[t]{3}{*}{5} & $M$ & 2.22 & 2.00 & 1.88 \\
\hline & $\mathrm{SD}$ & 0.52 & 0.61 & 0.64 \\
\hline & Median & 2.50 & 2.00 & 2.00 \\
\hline \multirow[t]{3}{*}{10} & $M$ & 4.48 & 3.97 & 3.55 \\
\hline & $\mathrm{SD}$ & 1.22 & 1.43 & 1.49 \\
\hline & Median & 5.00 & 4.00 & 4.00 \\
\hline \multirow[t]{3}{*}{30} & $M$ & 12.27 & 11.30 & 11.04 \\
\hline & $\mathrm{SD}$ & 4.07 & 4.38 & 4.63 \\
\hline & Median & 15.00 & 12.41 & 10.00 \\
\hline \multirow[t]{3}{*}{50} & $M$ & 20.71 & 18.87 & 17.16 \\
\hline & $\mathrm{SD}$ & 6.28 & 7.71 & 7.15 \\
\hline & Median & 25.00 & 20.00 & 17.50 \\
\hline \multirow[t]{3}{*}{100} & $M$ & 36.42 & 37.44 & 32.02 \\
\hline & $\mathrm{SD}$ & 39.65 & 14.87 & 14.91 \\
\hline & Median & 50.00 & 37.50 & 30.00 \\
\hline \multirow[t]{3}{*}{1000} & $M$ & 426.04 & 349.80 & 285.38 \\
\hline & $\mathrm{SD}$ & 191.81 & 163.21 & 167.57 \\
\hline & Median & 500.00 & 387.50 & 300.00 \\
\hline \multirow[t]{4}{*}{1 million } & $M$ & 445,358 & 342,164 & 294,187 \\
\hline & $\mathrm{SD}$ & 205,685 & 246,521 & 211,333 \\
\hline & Median & 500,000 & 325,000 & 300,000 \\
\hline & & $59 \leqslant n \leqslant 60$ & $56 \leqslant n \leqslant 58$ & $n=49$ \\
\hline
\end{tabular}

information $\times$ amount $(F(3,339)=10.76, p<0.001)$. The results indicate that complete information led to larger offers than in the partial information conditions, particularly with the larger amounts: offerers shaded M\&Ms as well as money.

\subsubsection{Responses}

Analysis of responses to $\$ 10$ ultimatum offers yielded effects for information $(F(2,368)=48.98, \quad p<0.001)$ and grade $\times$ information $(F(4,368)=3.60, p<0.005)$. The interaction (see Table 6) indicates little difference between the no strings and partial information conditions and a clear increase in lowest acceptable offers with complete information, as in previous studies. This supports Hypothesis 5. Sixth graders stated that they 
Table 6

Respondents' lowest acceptable offers (in dollars, Study 2)

\begin{tabular}{lccc}
\hline Grade & No Strings & Partial & Complete \\
\hline Sixth & & & \\
$M$ & 0.37 & 0.18 & 1.53 \\
Median & 0.04 & 0.10 & 0.50 \\
$n$ & 59 & 55 & 56 \\
Ninth & & & \\
$M$ & 0.395 & 0.48 & 1.665 \\
Median & 0.01 & 0.05 & 1.00 \\
$n$ & 58 & 52 & 55 \\
College & & & 1.12 \\
$M$ & 0.42 & 0.51 & 1.00 \\
Median & 0.05 & 0.05 & 138 \\
$n$ & 90 & 140 & \\
\hline
\end{tabular}

Note: Offerers divided $\$ 10$, but this was only known to respondents in the complete information condition.

were willing to accept less in the complete information condition than ninth graders and college students, supporting Hypothesis 4.

Analysis of lowest acceptable offers across monetary amounts in complete information yielded significant effects for grade $(F(2,125)=15.18, p<0.001)$ and for grade $\times$ amount $(F(2,244)=4.11, p<0.01)$. (See Table 7 , for means and medians.) As amounts increased, sixth graders required somewhat larger offers than ninth graders who required considerably more than college students, contrary to Hypothesis 4. Most college students showed a willingness to take very small offers, especially when the amounts were large (e.g., they accepted a median minimum offer of $\$ 100$ when they knew that $\$ 1$ million was being divided).

The analysis of responses to M\&M offers yielded one effect, for information $(F(1,16)=16.00, p<0.001)$. Sixth and ninth graders were willing to accept fewer M\&Ms $(M=1.80$; median $=1.00)$ when they did not know how many were being divided. They required more $(M=2.40$; median $=2.00)$ when they knew that $10 \mathrm{M} \& \mathrm{Ms}$ were being divided, supporting Hypothesis 5.

Fewer respondents accepted one penny in this study, compared to Study 1. Over both information conditions, sixth and ninth graders accepted one penny about $20 \%$ of the time; for college students, it was only $9 \%$. For M\&Ms, sixth graders accepted one $36 \%$ of the time and ninth graders accepted one $53 \%$ of the time. As with the younger children, one M\&M was accepted more frequently than one penny for sixth and ninth graders $(F(1,116)=44.75, p<0.001)$. 
Table 7

Older respondents' lowest acceptable offers (in dollars) for complete information conditions only (percentages in parentheses)

\begin{tabular}{|c|c|c|c|c|}
\hline \multicolumn{2}{|c|}{ Amount divided (\$) } & \multicolumn{3}{|l|}{ Grade } \\
\hline & & Sixth & Ninth & College \\
\hline \multirow[t]{3}{*}{10} & $M$ & $1.53(15.3)$ & $1.67(16.7)$ & $1.12(11.2)$ \\
\hline & SD & 1.90 & 1.92 & 1.46 \\
\hline & Median & $0.50(5.0)$ & $1.00(10.0)$ & $1.00(10.0)$ \\
\hline \multirow[t]{3}{*}{30} & $M$ & $8.19(27.3)$ & $7.75(25.8)$ & $3.62(12.1)$ \\
\hline & SD & 6.68 & 6.29 & 4.81 \\
\hline & Median & $5.00(16.7)$ & $10.00(33.3)$ & $1.50(5.0)$ \\
\hline \multirow[t]{3}{*}{50} & $M$ & $17.10(34.2)$ & $14.77(29.5)$ & $8.01(16.0)$ \\
\hline & SD & 12.58 & 11.39 & 8.60 \\
\hline & Median & $20.00(40.0)$ & $15.00(30.0)$ & $4.75(9.5)$ \\
\hline \multirow[t]{3}{*}{100} & $M$ & $40.29(40.3)$ & $34.05(34.0)$ & $18.05(36.1)$ \\
\hline & SD & 25.55 & 23.71 & 17.95 \\
\hline & Median & $50.00(50.0)$ & $40.00(40.0)$ & $12.00(24.0)$ \\
\hline \multirow[t]{3}{*}{1000} & $M$ & $362.59(36.3)$ & $320.35(32.0)$ & $74.09(7.4)$ \\
\hline & SD & 272.01 & 272.33 & 136.34 \\
\hline & Median & $500.00(50.0)$ & $400.00(40.0)$ & $15.00(0.15)$ \\
\hline \multirow[t]{4}{*}{1 million } & $M$ & 283,994 (28.4) & $150,453(15.0)$ & $44,253(4.4)$ \\
\hline & SD & 303,863 & 215,672 & 123,865 \\
\hline & Median & $200,000(20.0)$ & $4,000(0.4)$ & $100(0.01)$ \\
\hline & & $52 \leqslant n \leqslant 59$ & $52 \leqslant n \leqslant 58$ & $n=49$ \\
\hline
\end{tabular}

\subsubsection{Correlational analyses}

As in Study 1, respondents were internally consistent: their responses to M\&M and monetary offers were highly correlated; all 12 correlations were significant $(0.18<r<0.87, p<0.05)$. Correlations among and between monetary and M\&M offers were also strong, with 227 of 253 significant. Like the results for younger children, overall correlations between responses and offers were low, with only 22 of 106 significant. For sixth and ninth graders, the correlations were not significant $(-0.21 \leqslant r \leqslant 0.29)$. But for college students, the relationships were all positive and tended to be significant $(0.33 \leqslant r \leqslant 0.44 ; n=140)$. Thus, the younger groups were not particularly consistent when they shifted from being respondents to offerers, but college students were.

Analysis of the sixth graders' responses and offers in the two studies yielded only one significant effect: they required larger partial information offers on the questionnaires (Mean $=18.2$ cents) than they did when they responded one-on-one $[\mathrm{Mean}=5.81$ cents; $F(1,91)=6.92, \quad p<0.01]$. 
Although this difference might raise concerns about the comparability of the procedures in the two studies, the fact that questionnaire respondents had seen larger amounts (i.e., questions asking them whether they would accept amounts up to $\$ 5$ in the no strings condition) while face-to-face respondents were asked whether they would accept smaller offers in ascending order (1 cent, 2 cents, etc.) may have contributed to this difference.

\subsection{Discussion}

The results from Study 2 provide a bridge from the findings of Study 1 to previous research on adults. They help identify some of the developmental differences in ultimatum bargaining between the two samples of different ages, particularly due to the strength of the results in Study 2.

Hypothesis 5 was strongly supported again (see Table 8), this time for both dollars and M\&Ms. This suggests that the acceptance of small partial information offers is quite robust.

Hypothesis 4 led to outcomes that were different for money and M\&Ms, and for partial and complete information. While sixth graders reported being willing to accept fewer M\&Ms and less money in the $\$ 10$ complete information condition than ninth graders or college students, they were less willing to accept small offers when higher amounts were being divided. These results raise issues concerning potentially different perceptions of these two commodities and of the different monetary amounts. Although the findings

Table 8

Evaluation of the hypotheses in the two studies

\begin{tabular}{|c|c|c|}
\hline Hypotheses & Study 1 & Study 2 \\
\hline $\begin{array}{l}\text { 1. More equal offers by } \\
\text { younger children }\end{array}$ & $\begin{array}{l}\text { Mixed support (from } \\
\text { kindergartners) }\end{array}$ & $\begin{array}{l}\text { Strong support (\$\$) No } \\
\text { evidence }(\mathrm{M} \& \mathrm{Ms})\end{array}$ \\
\hline $\begin{array}{l}\text { 1a. More generous offers by } \\
\text { older children }\end{array}$ & $\begin{array}{l}\text { 6th grade males }(\$ \$) \text { No } \\
\text { evidence }(\mathrm{M} \& \mathrm{Ms})\end{array}$ & $\begin{array}{l}\text { Exactly the reverse }(\$ \$) \text { No } \\
\text { evidence (M\&Ms) }\end{array}$ \\
\hline $\begin{array}{l}\text { 2. Strategic offers increase } \\
\text { with age }\end{array}$ & $\begin{array}{l}\text { No clear support (\$\$ and } \\
\text { M\&Ms) }\end{array}$ & $\begin{array}{l}\text { Strong support }(\$ \$) \text { No } \\
\text { evidence (M\&Ms) }\end{array}$ \\
\hline 3. Larger offers by girls & $\begin{array}{l}\text { For } 5 \& 11 \text { M\&Ms Partial } \\
\text { information }(\$ \$)\end{array}$ & $\begin{array}{l}\text { For raw offers and Partial } \\
\text { information }(\$ \$)\end{array}$ \\
\hline $\begin{array}{l}\text { 4. Smaller offers accepted by } \\
\text { younger children }\end{array}$ & Some support (kindergartners) & Mixed support ( $\$ \$$ and $M \& M s$ ) \\
\hline $\begin{array}{l}\text { 5. Smaller offers accepted in } \\
\text { partial information }\end{array}$ & Strong support $(\$ \$)$ & Strong support ( $\$ \$$ and $M \& M s)$ \\
\hline
\end{tabular}


match those of Study 1 qualitatively, the respondents in this study tended to accept one penny or one M\&M less often than the younger respondents in Study 1 . Thus, the results for Hypothesis 4 continue to be mixed.

Hypothesis 3 found similar support in both studies. As before, sixth and ninth grade girls tended to offer more than boys, particularly in the partial information condition. Clearly, females take less strategic advantage of information asymmetries than males, across all ages studied here.

Hypothesis 2 was strongly supported for monetary offers: strategic behavior did increase with age. This was particularly true for college students whose behaviors as offerers and respondents were correlated. Since college students reported thinking that their peers were willing to accept small offers (as most of them were), then they could effectively offer them less, especially when respondents did not know how much was being offered. While third grade boys in Study 1 seemed to also grasp the possibility for strategic behavior, the increase in strategic behavior with age is particularly apparent in Study 2. It may be that the consistency that seems to come with age is necessary for this effect to fully appear.

With this older set of offerers, Hypothesis 1a received no support, while Hypothesis 1, which posited that younger children would make more equal offers, was strongly supported (again, only for dollars). Sixth graders, particularly sixth grade girls, were most likely to make 50-50 offers, and this tendency dissipated with age and increasing monetary amounts.

\section{General discussion}

The data from these two studies provide a first step in the investigation of the development of bargaining behavior in ultimatum games. Starting with kindergartners, we observe a number of different behaviors, including their seeming inability to refuse offers of one M\&M, their apparent generosity when making offers of coins or M\&Ms, and no evidence of guile or strategic behavior whatsoever. Our youngest participants were the only ones to give all of the money or the candy away. This may have reflected altruism (e.g., "because he doesn't have much"); it may also represent a different script, since at least two children said that they gave everything to the other child "so he wouldn't bother me." This fits the underlying notions of the model of justice by Damon (1980) (although his model predicted equal splits). At the same time, it provides a foundation for interpreting the behavior of the older children. 
Third graders were particularly intriguing. They tended to be strategic offerers when they were dividing money but they were extremely fair when they were offering or responding to $\mathrm{M} \& \mathrm{M}$ offers. Boys and girls revealed different kinds of strategies as well, with boys being blatantly more strategic with monetary offers and girls being subtly more generous with M\&M offers, offering more than half when they were dividing odd numbers of candies.

Sixth grade boys, in contrast, did not follow the trend established by third graders: few of their monetary offers were strategic (although these few were extremely strategic); instead most tended to be perfectly fair, making 50-50 offers. This represents a developmental discontinuity in the data: either the third grade boys in this sample were more strategic than might be expected or sixth grade boys were more generous. The data from Study 2 suggests that the former may be the more appropriate interpretation, since the format change from Study 1 to Study 2 led to almost no differences in sixth graders' behavior. In fact, a relatively smooth trend across ages was quite strong in Study 2. Especially for the larger amounts of money, sixth graders indicated that offers needed to be larger to be acceptable, larger than those demanded by ninth graders or college students. At the same time, they offered more. Only the college students showed any tendency to be consistent across the two roles of offerer and respondent; they were also the only participants to express a willingness to accept very small offers.

Tests of the hypotheses indicated that, in general, younger children offered more and accepted less than older children or adults. Most kindergartners did not reject either one penny or one M\&M. In addition, with increasing age, respondents other than college students appeared less willing to accept low offers.

Girls were consistent across both studies, offering more than boys in the partial information conditions. They also tended to be fair or perfectly fair more often than males. When they did act strategically, they were only moderately strategic, shading their offers only slightly.

The acceptance of small offers by younger respondents, Hypothesis 4, received mixed support in both studies. Kindergartners accepted one penny and one M\&M more than older children, and acceptances of one penny and one M\&M tended to decrease with age (although third graders accepted less than expected). Sixth graders in Study 2 accepted less than older respondents in the complete information conditions when monetary amounts were small, but not when amounts were large. Thus, the data for acceptances may warrant additional investigation. (This is also true for adult populations as a whole.) 
Respondents were quite consistent, however, in accepting smaller offers in the partial information conditions. When no information was available about the amount to be divided and respondents could not know how much offerers would benefit, respondents tended to accept very small amounts. These findings replicate previous findings and show robust support for the subgame-perfect predictions for many age groups in partial information conditions.

The fact that our respondents tended to accept offers of one M\&M more often than offers of one penny suggests that respondents evaluated them quite differently. Their emotional reactions when the game switched to M\&Ms were quite clear: they were much more physically active and smiled more when they knew that the currency had changed to M\&Ms. Thus, future research might investigate whether immediately disposable, attractive commodities like M\&Ms lead people to act as if anything is clearly better than nothing.

\subsection{Limitations and future research}

Since this study was not conducted longitudinally, the observed differences may not reflect true developmental differences. In addition, the payoffs may have been conceptualized differently by the older and younger participants. Constraints by administrators and the risk of contaminating future respondents made it impossible to provide direct incentives to anyone except the college students. And, finally, we could not counter-balance the order of conditions (e.g., all coin offers preceded M\&M offers in Study 1). This reduced the strength of the design but ensured that the participants attended directly to the task.

These limitations should lead to cautious conclusions. At the same time, the studies provide the first data that we know of on these issues. As such, they provide the groundwork for additional research. In particular, the notion that third grade boys were obviously strategic (one asked the experimenter before making his offer, "Now, he doesn't know what this amount is, right?") when they were dividing money warrants additional investigation. Whether this finding can be replicated, whether it might originate earlier (with first or second graders, at ages 7 or 8), how it relates to other abilities (e.g., computational) or values, and why it appears for money and not M\&Ms are all open questions. The more general question concerning the apparent inconsistencies across commodities also suggests the need for additional research - especially since, unlike sixth graders, ninth graders ap- 
peared to be strategic for both their monetary and their M\&M offers. Thus, the inconsistencies of sixth grade boys' monetary and M\&M offers may reflect one stage in a developing trend.

Many third graders exercised the most stringent fairness criteria we observed in this study. Most made only 50-50 M\&M offers, regardless of the information condition, and 13 of 40 third graders rejected offers that favored the other person and offers that favored themselves. They upheld an extreme standard for fairness even when offerers freely asked for less than they offered. This set of third graders more than supported the observations of Damon (1980) for 5- to 7-year-olds, i.e., tended to often no more and no less than $50-50$ for both bargainers. At approximately 9 years of age, however, they were older than predicted by the model of Damon (1980). Instead, they are in line with the early results of Handlon and Gross (1959).

This result also suggests that strategic bargaining by young boys may be restricted to monetary negotiations. The qualitative differences between money and M\&Ms were highlighted by the fact that, for every age group, more respondents accepted offers of one M\&M than offers of one penny, in both the complete and partial information conditions. (Of a total of 241 respondents, $98(41 \%)$ accepted 1 penny in the partial information conditions; $134(56 \%)$ accepted one M\&M. For complete information, $62(26 \%)$ accepted one cent; 104 (43\%) accepted one M\&M.)

The sixth and ninth graders' behaviors approximated but were less extreme than those of the college students in many ways. Sixth graders were less willing to accept low offers and both sixth and ninth graders made higher offers than college students. There were two other noteworthy differences among the older groups. First, college students said that they were willing, on average, to accept extremely low offers as respondents; this more than offset the drop in their own offers as the amounts to be divided increased. And second, unlike all the younger participants, their offers and responses were significantly correlated.

While the younger participants offered more and accepted less, the only adults in these studies, college students, offered less and accepted even less than the younger respondents. This shift, and the internally consistent offer and response behavior of the college students, suggests the possibility of a qualitative shift between ninth grade and college, at least in this sample. In particular, college students moved closer to matching the predictions of economic theory, offering less and accepting less, even with complete information. For them, reductions in offers were matched by reductions in what they were willing to accept. This suggests a distinct relaxation of the stringent 
fairness criteria exercised by younger children. With increasing age, people may be willing to accept much less than half, especially as the amount to be divided increases. And even these numbers may be inflated, since people's ability to reject large amounts of real money (e.g., sixth graders who said they would reject $\$ 300$ or more when $\$ 1000$ is being divided) is clearly open to question.

Alternative explanations for this apparent shift to consistency by college students include the possibility that they may be less affected by and less prone to quick emotional reactions. Recent research by Frank et al. (1993) also suggests another explanation: that college students have had the chance to study economics and, as a result, have become more consistent in their bargaining strategies: note in this context that the subjects in the present experiment were involved in a management class. These possibilities open doors for future research.

The results are also consistent with the notion that children become more competitive as they get older (e.g., Toda et al., 1978). It may be that children's increasing competitiveness is fueled by a concomitant increase in strategic behavior, which allows them to achieve their competitive goals (i.e., to do better than the other person).

Straub and Murnighan (1995) found that small amounts of money (e.g., less than a quarter or 50 cents) were almost meaningless to many respondents (since "they wouldn't work in a parking meter or a soda machine"). Some children also refused very small amounts of money (e.g., a penny or two). As one third grade boy, who rejected the offer of a penny, put it: "You can't buy anything with a penny. It's not going to do you a lot of good, unless you save up your pennies, which could take a very long time, because it takes 25 to equal a quarter." He rejected 2, 3, 4, and 5 cents as well, but accepted 10, saying "You can buy a piece of candy with 10 cents." Thus, even when people did reject small amounts of money, it may have been because they judged the amounts to be subjectively (rather than objectively) meaningless.

Economic models rarely address the behavior of children. But the continued support found here for Hypothesis 5 suggests that subgame-perfect predictions are also applicable in partial information conditions for very young respondents. As children get older, as they know how much is being divided, or if they are making rather than responding to ultimatum offers, however, they provide much less support for the subgame-perfect predictions.

Like adults, children rejected small, complete information offers and offered more than small amounts. This same third grade boy offered an ex- 
planation that has not been well incorporated in economic models. When he made a partial information offer dividing $\$ 1$, he offered 50 cents and explained: "Then it would be $50-50$. Both of us would have 50 cents." When he made a similar offer that was complete information, he said, " 25 cents. No, 60 cents, because sometimes I like to give people some more than I got. Some I let them have all of it, and I just keep what I have. Sometimes money doesn't matter; it depends on what I feel."

These quotes are included to show that, while children increasingly shape their behaviors to match those of adults, they start with a broad base of reactions, some economic and some concerning fairness. More research on how these two concerns develop and how they affect bargaining behavior and other interactions certainly seems warranted. We hope that the research reported here can provide some of the early groundwork for both theoretical and empirical advances in this area.

\section{Acknowledgements}

We would like to gratefully acknowledge the assistance of Susan Bruce, Robert Handlin, Lynn and Howard Thomas, Susan Zola, and the school systems of Urbana, Champaign, and Mahomet, Illinois, for providing us with the opportunity to conduct this study. We also thank Maria Crisafi, Chuck McClintock, Greg Oldham, Madan Pillutla, Paul Straub, and two anonymous reviewers, for their constructive comments on an earlier version of this paper, and Leann Mischel for her assistance in collecting the data. Portions of this paper were completed while the first author was a faculty member at the University of Illinois and while he was a director of the Summer Institute on Conflict and Negotiation Research, 1992, at the Center for Advanced Study in the Behavioral Sciences, Stanford, California. The support of the Andrew Mellon Foundation and the Social Sciences and Humanities Research Council of Canada is sincerely appreciated.

\section{References}

Adams, J.S., 1963. Toward an understanding of inequity. Journal of Abnormal and Social Psychology 67 , $422-436$.

van Avermaet, E., McClintock, C.G., 1988. Intergroup fairness and bias in children. European Journal of Social Psychology 18, 407-428.

Bazerman, M.H., 1994. Judgment in Managerial Decision Making, 3rd ed. Wiley, New York. 
Bolle, F., 1990. High reward experiments without high expenditure for the experimenter. Journal of Economic Psychology 11, 157-167.

Bolton, G.E., Zwick, R., 1995. Anonymity versus punishment in ultimatum bargaining. Games and Economic Behavior 10, 95-121.

Croson, R.T.A., 1993. Information in ultimatum games: An experimental study. Mimeo, Harvard University.

Damon, W., 1980. Patterns of change in children's social reasoning: A two-year longitudinal study. Child Development 51, 1010-1017.

Frank, R.H., Gilovich, T., Regan, D.T., 1993. Does studying economics inhibit cooperation? Journal of Economic Perspectives 7, 159-171.

Güth, W., Schmittberger, R., Schwarze, B., 1982. An experimental analysis of ultimatum bargaining. Journal of Economic Behavior and Organization 3, 367-388.

Güth, W., Tietz, R., 1987. Ultimatum bargaining for a shrinking cake - An experimental analysis. Mimeo.

Güth, W., Tietz, R., 1990. Ultimatum bargaining behavior: A survey and comparison of experimental results. Journal of Economic Psychology 11, 417-449.

Handlon, B.J., Gross, P., 1959. The development of sharing behavior. Journal of Abnormal and Social Psychology 59, 425-428.

Harrison, G.W., McCabe, K.A., 1992. Expectations and fairness in a simple bargaining experiment. Paper presented at the Public Choice Society meetings, New Orleans.

Hoffman, E., McCabe, K., Shachat, K., Smith, V., 1994. Preferences, property rights, and anonymity in bargaining games. Games and Economic Behavior 7, 346-380.

Hook, J., Cook, T.D., 1979. Equity theory and the cognitive ability of children. Psychological Bulletin 86, 429-445.

Kagan, S., Madsen, M., 1972. Rivalry in Anglo-American and Mexican children of two ages. Journal of Personality and Social Psychology 24, 214-220.

Kagel, J., Kim, C., Moser, D., 1992. Ultimatum games with asymmetric payoffs. Mimeo, University of Pittsburgh.

Kahn, L.M., Murnighan, J.K., 1993. A general experiment on bargaining in demand games with outside options. American Economic Review, in press.

Keil, L.J., 1986. Rules, reciprocity, and rewards: A developmental study of resource allocation in social interaction. Journal of Experimental Social Psychology 22, 419-435.

Keil, L.J., McClintock, C.G., 1983. A developmental perspective on distributive justice. In: Messick, D., Cook, K. (Eds.), Theories of equity: psychological and sociological perspectives. Praeger, New York.

Kohlberg, L., 1976. Moral stages and motivation. In: Likona, T., (Ed.), Moral Development and Behavior. Holt, Rinehart \& Winston, New York.

Lea, S.E.G., Tarpy, R.M., Webley, P., 1987. The Individual in the Economy. Cambridge University Press, Cambridge.

Lerner, M.J., 1974. The justice motive: "Equity" and "parity" among children. Journal of Personality and Social Psychology 29, 539-550.

Maxwell, S.E., Delaney, H.D., 1990. Designing experiments and analyzing data: A model comparison procedure. Wadsworth, Belmont CA.

McClintock, C.G., Moskowitz, J.M., McClintock, E., 1977. Variations in preferences for individualistic, competitive, and cooperative outcomes as a function of age, game class, and task in nursery school children. Child Development 48, 1080-1085.

Mischel, W., Metzner, R., 1962. Preference for delayed reward as a function of age, intelligence, and length of delay interval. Journal of Abnormal and Social Psychology 64, 425-431.

Morgan, W., Sawyer, J., 1967. Bargaining, expectations, and the preference for equality over equity. Journal of Personality and Social Psychology 6, 139-149.

Murnighan, J.K., 1991. The dynamics of bargaining games. Prentice Hall, Englewood Cliffs, NJ. 
Neelin, J., Sonnenschein, H., Spiegel, M., 1988. A further test of noncooperative bargaining theory. American Economic Review 78, 824-836.

Ochs, J., Roth, A., 1989. An experimental study of sequential bargaining. American Economic Review 79, $355-384$.

Piaget, J., 1965. The moral judgment of the child. Free Press, New York (originally published in 1932).

Pillutla, M.M., Murnighan, J.K., 1995. Being fair or appearing fair: strategic behavior in ultimatum bargaining. Academy of Management Journal 38, 1408-1426.

Roth, A.E., 1995. Bargaining experiments. In: Kagel, J.H. and Roth, A.E. (Eds.), The Handbook of Experimental Economics. Princeton University Press, Princeton, NJ.

Roth, A.E., Prasnikar, V., Okuno-Fujiwara, M., Zamir, S., 1991. Bargaining and market behavior in Jerusalem, Ljubljana, Pittsburgh, and Tokyo: An experimental study. American Economic Review 81, $1068-1095$.

Selten, R., 1965. Spieltheoretische behandlung eines oligopol modells mit nachfragetragheit. Zeitschrift fur Gesamte Staatswissenschaft 121, 301-324.

Stahl, I., 1972. Bargaining Theory. Economic Research Institute, Stockholm School of Economics, Stockholm.

Straub, P.G., Murnighan, J.K., 1995. An experimental investigation of ultimatums: Common knowledge, fairness, expectations, and lowest acceptable offers. Journal of Economic Behavior and Organization $27,345-364$.

Streater, A.L., Chertkoff, J.M., 1976. Distribution of rewards in a triad: A developmental test of equity theory. Child Development 47, 800-805.

Thaler, R.H., 1987. The psychology of choice and the assumptions of economics. In: Roth, A.E. (Ed.), Laboratory Experiments in Economics: Six Points of View. Cambridge Univ. Press, Cambridge.

Toda, M., Shinotsuka, H., McClintock, C.G., Stech, F.J., 1978. Development of competitive behavior as a function of culture, age, and social comparison. Journal of Personality and Social Psychology 36, 825839.

Webley, P., Lea, S.E.G., 1993. Towards a more realistic psychology of economic socialization. Journal of Economic Psychology-, 14, 461-472.

Zarbatany, L., Hartmann, D.P., Gelfand, D.M., 1985. Why does children's generosity increase with age: susceptibility to experimenter influence or altruism? Child Development 56, 746-756. 